\title{
Ambient UV-B radiation decreases photosynthesis in high arctic Vaccinium
} uliginosum.

Albert, Kristian; Ro-Poulsen, Helge; N. Mikkelsen, Teis

Published in:

Physiologia Plantarum : An International Journal for Plant Biology

DOI:

10.1111/j.1399-3054.2008.01065.x

Publication date:

2008

Document version

Publisher's PDF, also known as Version of record

Citation for published version (APA):

Albert, K., Ro-Poulsen, H., \& N. Mikkelsen, T. (2008). Ambient UV-B radiation decreases photosynthesis in high arctic Vaccinium uliginosum. Physiologia Plantarum : An International Journal for Plant Biology, 133(2), $199-210$. https://doi.org/10.1111/j.1399-3054.2008.01065.x 


\title{
Ambient UV-B radiation decreases photosynthesis in high arctic Vaccinium uliginosum
}

\author{
Kristian R. Albert ${ }^{\mathrm{a}, *}$, Teis N. Mikkelsen ${ }^{\mathrm{b}}$ and Helge Ro-Poulsen ${ }^{\mathrm{a}}$ \\ ${ }^{a}$ Department of Terrestrial Ecology, Biological Institute, University of Copenhagen, Oester Farimagsgade 2D, DK-1353 Copenhagen K, Denmark \\ biosystems Department, Risø National Laboratory, Technical University of Denmark, DK-4000 Roskilde, Denmark
}

\section{Correspondence \\ *Corresponding author, \\ e-mail: kristiana@bi.ku.dk}

Received 11 July 2007;

revised 26 November 2007

doi: 10.1111/j.1399-3054.2008.01065.x

\begin{abstract}
An UV-B-exclusion experiment was established in high arctic Zackenberg, Northeast Greenland, to investigate the possible effects of ambient UV-B on plant performance. During almost a whole growing season, canopy gas exchange and $\mathrm{Chl}$ fluorescence were measured on Vaccinium uliginosum (bog blueberry). Leaf area, biomass, carbon, nitrogen and UV-B-absorbing compounds were determined from a late season harvest. Compared with the reduced UV-B treatment, the plants in ambient UV-B were found to have a higher content of UV-B-absorbing compounds, and canopy net photosynthesis was as an average $23 \%$ lower during the season. By means of the JIP-test, it was found that the potential of processing light energy through the photosynthetic machinery was slightly reduced in ambient UVB. This indicates that not only the UV-B effects on PSII may be responsible for some of the observed reduction of photosynthesis but also the effects on other parts of the photosynthetic machinery, e.g. the Calvin cycle, might be important. The $60 \%$ reduction of the UV-B irradiance used in this study implies a higher relative change in the UV-B load than many of the supplemental experiments do, but the substantial effect on photosynthesis clearly indicates that $V$. uliginosum is negatively affected by the current level of UV-B.
\end{abstract}

\section{Introduction}

Stratospheric ozone depletion increases UV-B radiation (280-315 nm) in the biosphere (Madronich et al. 1998), and although this may be mitigated by increased cloudiness, it has raised concerns about UV-B impacts on plants (Caldwell et al. 1998, Rozema et al. 1997; for a critical view, see Allen et al. 1998). The UV-B exposure in the Arctic region is currently considered to be near the maximum, and the ozone column is predicted to recover towards the middle of the century (WMO 2003). Furthermore, not only the relative increase in UV-B irradiance has been occurring most rapidly at high latitudes but also the absolute net depletion of ozone has been highest, resulting in the potentially highest impact on the vegetation there (Björn et al. 1999, Paul 2001). Moreover, arctic plants are exposed to extreme living conditions with respect to climate and the limit of their distribution. Also, the longevity of many arctic plants makes them adapt only slowly to environmental changes (Callaghan and Jonasson 1995). Thus, additional stress factors of importance may affect arctic plants negatively.

Arctic plants have in general been shown to be susceptible to increases in incident UV-B (Johanson et al. 1995, Gehrke et al. 1996), but few reports from exclusion studies addressing the impact on vegetation are available from the Arctic (Albert et al. 2005, Bredahl et al. 2004, Phoenix et al. 2002, Rinnan et al. 2005). Some

Abbreviations - CS, cross-section; RC, reaction centre. 
longer term UV-exclusion studies have been conducted in South America (Robson et al. 2003, Rousseaux et al. 1999), Antarctic (Day et al. 2001, Xiong and Day 2001) and elsewhere. In the Arctic, UV reduction resulted in increased flowering and berry production and a decrease in UV-B-absorbing compounds in sub-Arctic dwarf scrubs (Phoenix et al. 2002). UV reduction in high Arctic studies, although of short duration, resulted in increased $\mathrm{F}_{\mathrm{V}} / \mathrm{F}_{\mathrm{M}}$ in Salix arctica and Vaccinium uliginosum and reduced the stomatal conductance and internal $\mathrm{CO}_{2}$ concentration in Salix (Bredal et al. 2004). Moreover, by optimizing the natural irradiance by leaf angle control, UV reduction was observed to have positive impacts on almost all measured and derived fluorescence parameters on $S$. arctica, i.e. $\mathrm{F}_{\mathrm{V}} / \mathrm{F}_{\mathrm{M}}$ and $\mathrm{PI}$ indexes (Albert et al. 2005).

Several studies have shown that PSII is sensitive to UV-B (Melis et al. 1992, Strid et al. 1990). However, other studies (Allen et al. 1997, Nogués and Baker 1995) have questioned whether PSII damage is the primary cause of reduction in photosynthesis. It seems that UV-B-induced reduction in photosynthesis can occur prior to, or in absence of, depressions in PSII function and probably involves impairments in the Calvin cycle (Allen et al. 1999, Nogués and Baker 1995). Because UV-B screening pigments such as flavonoids (Caldwell and Flint 1994, van de Staaij et al. 1995) and hydroxycinnamates (Burchard et al. 2000) to some degree do protect against deleterious effects of UV-B (Alenius et al. 1995), they probably influence photosynthetic processes in underlying tissues.

This experiment aimed at investigating whether the photosynthetic performance of high arctic vegetation would improve if UV-B irradiance were reduced. The manipulative approach chosen was to reduce the UV-B radiation load on the vegetation by means of filters to assess effects of present-day UV-B radiation. This approach excludes the spectral matching problems of natural irradiation experienced in many earlier UV-B supplementation experiments (Flint et al. 2003). A robust measure of photosynthesis was obtained by canopy-level $\mathrm{CO}_{2}$ gas exchange measurements. In addition, the processing of light energy through PSII was measured by recording transients of $\mathrm{Chl}$ a fluorescence using the JIPtest and associated parameters (Strasser et al. 2004), a methodology discussed by Lazár (2006), Strasser et al. (2000) and Strasser et al. (2004).

It is hypothesized that (1) more UV-B-absorbing compounds are found at ambient compared with the reduced UV-B level and (2) PSII performance (i.e. estimated electron transfer and performance indexes) is higher at reduced UV-B with (3) possible improvements of the photosynthetic performance.

\section{Materials and methods}

\section{Experimental site}

The fieldwork was carried out in a high arctic heathland at Zackenberg Research Station, Northeast Greenland $\left(74^{\circ} 30^{\prime} \mathrm{N}, 21^{\circ} \mathrm{E}\right)$, during July and August 2002. The plant species investigated was the long-lived deciduous dwarf shrub V. uliginosum L., ssp. microphyllum Lge., dominating the vegetation cover in the experimental area. High temperatures induced a fast snowmelt beginning in early June, resulting in snowfree vegetation from midJune. Leaves were fully developed and expanded when the experiments were initiated. Senescence period began early August after a period of cool weather from late July, which continued throughout August (Rasch and Canning 2003).

\section{Experimental set-up and treatments}

The aim was to establish plots where parts of the UV spectrum in natural daylight were reduced by filtering the solar radiation through a Mylar ${ }^{\circledR}$ film (type D. DuPont Teijin Films, Wilmington, DE). In general, the Mylar filter transmits $\lambda>320 \mathrm{~nm}$ (Cybulski and Peterjohn 1999). A Teflon ${ }^{\circledR}$ filter (Fluoretek AB, Knivsta, Sweden), which is transparent to UV, was used as control. In general, it transmits $\lambda>280 \mathrm{~nm}$ (Cybulski and Peterjohn 1999). Measurements in the experimental area with a broadband cosine corrected UV-B sensor (UV-S-310-T; Scintec, Atmosphärenmesstechnik GmbH, Tübingen, Germany now manufactured as UV-S-B-T by Kipp and Zonen B.V., Delft, The Netherlands) showed that the plant canopy under the Teflon filter was exposed to about $91 \%$ of incoming UV-B but only to 39\% under the Mylar filter, with some variation depending on the exposure angle to the sun. PAR was reduced to $97 \%$ under the Teflon filter and $89 \%$ under the Mylar filters compared with open plots (Bredal et al. 2004). No deterioration of the filters was detected after exposure to field conditions (Bredal et al. 2004). In the following, Teflon is referred to as 'ambient UV-B' and Mylar as 'reduced UV-B'.

Individual Vaccinium plants were selected, and around each plant, circular 13.5-cm-diameter metal chamber bases were inserted approximately $5 \mathrm{~cm}$ into the soil to enable $\mathrm{CO}_{2}$ flux measurements. Above the bases, the filters were placed parallel to the soil surface approximately $10 \mathrm{~cm}$ above the canopy supported by $30 \times 30 \mathrm{~cm}$ aluminium frames. The plants were watered with 0.25 I per chamber base three times within the first week to ensure fine root reestablishment. This did not change soil moisture conditions between treatments. The species composition within the plots was totally 
dominated by Vaccinium plants ( $>95 \%$ ) and mosses, with some graminoids occurring in a few plots.

The experiment was a randomized design with 10 experimental plots beneath Mylar filter and 10 plots below Teflon filter. Measurements of $\mathrm{Chl}$ a fluorescence, gas exchange and microclimate were performed approximately every fourth day during approximately $4 \mathrm{~h}$ between 14:30 and 19:30 h.

\section{$\mathrm{Chl}$ a fluorescence and JIP-test}

Leaves were dark adapted for minimum 25 min before transients of $\mathrm{Chl}$ a fluorescence were measured with a Handy PEA (Hansatech Instruments Ltd., King's Lynn, Norfolk, UK) at $650 \mathrm{~nm}$ light with an intensity of $2500 \mu \mathrm{mol} \mathrm{m}{ }^{-2} \mathrm{~s}^{-1} \quad$ (Tsimilli-Michael and Strasser 2001). Measurements were performed on detached leaves in situ using a pincer to place excised leaves in dark adaptation clips. To avoid stripping of the canopy, five healthy top leaves of random leaf angle were sampled just outside the chamber base but still well within the filter covered area. For possible comparison of fluorescence and gas exchange parameters, the fluorescence recordings were initiated approximately at the same time as gas exchange measurements were taken.

From the fluorescence transient, the measured parameters $\left(F_{\mathrm{o}}=F_{50 \mu \mathrm{s},}, F_{K}=F_{300 \mu s}, \quad F_{J}=F_{2 m s}, \quad F_{1}=F_{30 m s,}\right.$ $\mathrm{F}_{\mathrm{M}}=\mathrm{F}_{\mathrm{P},}, \mathrm{tF}_{\mathrm{M}}$ and Area) lead to calculation and derivation of a range of new parameters according to Strasser et al. (2004). See also Albert et al. (2005) for a summary of all parameters and formulae. Briefly, the careful translation of the measured parameters into JIP-test parameters provides information on the stepwise flow of energy through PSII at different levels: (1) specific fluxes on the level per reaction centre $(\mathrm{RC})$ and these are for absorption $(\mathrm{ABS} / \mathrm{RC})$, trapping $\left(\mathrm{TR}_{\mathrm{o}} / \mathrm{RC}\right)$, dissipation $\left(\mathrm{DI}_{\mathrm{o}} / \mathrm{RC}\right)$ and electron transport $\left(\mathrm{ET}_{\mathrm{o}} / \mathrm{RC}\right)$ and (2) phenomenological fluxes on the level of the excited leaf cross-section (CS), and these are for absorption (ABS/CS), trapping $\left(\mathrm{TR}_{\mathrm{o}} / \mathrm{CS}\right)$, dissipation $\left(\mathrm{DI}_{\mathrm{o}} / \mathrm{CS}\right)$ and electron transport $\left(\mathrm{ET}_{\mathrm{o}} / \mathrm{CS}\right)$. These fluxes are interrelated and outlined in Fig. 1 as pipeline models with specific fluxes in the membrane model and the phenomenological fluxes in the leaf model. The JIP-test proposes equations to convert experimental fluorescence signals into biophysical or bioenergetic meaning (similar to Beer-Lambert's law, which transforms the fraction of transmitted light $\mathrm{T}$ into chemical concentration). Ideally, this is performed by measures of reflection or absorption or alternatively it is approximated by, i.e., florescence data. This approximation is performed by assuming that either $F_{O}$ or $F_{M}$ are reasonable measures of the absorption energy flux per excited CS of leaf sample (ABS/CS) in arbitrary units of
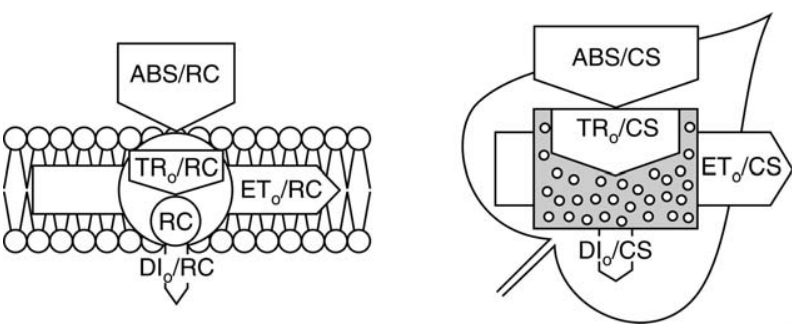

Fig. 1. Pipeline models. Left: The membrane model displaying specific fluxes per PSII RC. Right: The leaf model with phenomenological fluxes per leaf CS. See Materials and methods for JIP-test parameter presentation. Figures are modified with permission from Strasser et al. (2000).

a particular leaf sample in the dark-adapted state and then the phenomenological fluxes can be estimated. The specific and phenomenological fluxes are interrelated by the quantum efficiencies, which are (1) the maximum quantum yield (with all PSII RCs open) of primary photochemistry $\left(\mathrm{F}_{\mathrm{V}} / \mathrm{F}_{\mathrm{M}}\right)$, which in this terminology is equal to the efficiency by which an absorbed photon will be trapped by the PSII RC with the resultant reduction of $Q_{A}$ to $\mathrm{Q}_{\mathrm{A}}{ }^{-}(\mathrm{TR} / \mathrm{ABS})$, and (2) the efficiency by which a trapped exciton, having triggered the reduction of $\mathrm{Q}_{\mathrm{A}}$ to $\mathrm{Q}_{\mathrm{A}}{ }^{-}$can move an electron further than $\mathrm{Q}_{\mathrm{A}}{ }^{-}$into the intersystem electron transport chain $\left(\mathrm{ET}_{\mathrm{o}} / \mathrm{TR}_{\mathrm{o}}\right)$. Integrative parameters, so-called performance indexes, reflecting performance of the overall energy flow processing are (1) based on quantum efficiencies and hereby related to the situation of assuming equal absorption $\left(\mathrm{Pl}_{\mathrm{ABS}}\right)$ and (2) based on the phenomenological fluxes related to the per leaf CS level $\left(\mathrm{Pl}_{\mathrm{CSo}}\right.$ and $\left.\mathrm{Pl}_{\mathrm{CSm}}\right)$. Estimation of the density of active PSII reaction centres per leaf $\mathrm{CS}\left(\mathrm{RC} / \mathrm{CS}_{\mathrm{M}}\right)$ is also possible. Brief parameter descriptions are given in the Results section the first time each parameter occurs.

\section{Gas exchange}

Gas exchange was measured (CIRAS-1; PP systems, Hitchin, UK) and connected to an open system ventilated canopy chamber with an internal volume of 3 I (CPY-3 TPX and Stainless Steel ring; PP Systems, Hertfordshire,

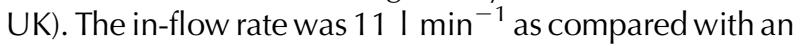
analysis sample rate at $300 \mathrm{ml} \mathrm{min}$. The transparent chamber was in place for 2-5 min before five successive readings were taken. The chamber was then darkened with a light-excluding wooden box and five more successive readings were then taken after a 5- to 8-min period.

At each measuring day during the season, a total of 50 leaves were collected from each treatment. Leaf area and dry weight were determined, and then correlations were calculated for each treatment. At the end of the season, the plots were harvested and the dry weight of leaves and aboveground stems in each plot was determined. Leaf 
area in each plot was then estimated from the correlation between leaf area and leaf weight for each treatment. During whole season, no significant differences in area and dry weight of the leaves were observed.

The gas exchange was calculated as $\mathrm{CO}_{2}$ flux ( $\mu$ mol $\left.\mathrm{m}^{-2} \mathrm{~s}^{-1}\right)=\Delta \mathrm{CO}_{2}(\mathrm{~V} \times 1000) /(\mathrm{A} \times 22.414 \times 1000 \times$ $60)$, where $\Delta \mathrm{CO}_{2}$ is the difference of $\mathrm{CO}_{2}$ concentration between the air supply and the chamber air in parts per million, $\mathrm{V}$ is the flow measured in $\mathrm{ml} \mathrm{min}^{-1}$ at STP through the chamber, $A$ is the canopy leaf area $\left(\mathrm{cm}^{2}\right)$ estimated from the final harvest and 22.414 I is the molar volume at STP (CPY-3, operators manual version 3.10; PP Systems). Net photosynthesis $=\mathrm{CO}_{2}$ uptake in light, respiration $=\mathrm{CO}_{2}$ efflux in dark, and gross photosynthesis $=\mathrm{CO}_{2}$ uptake in light $+\mathrm{CO}_{2}$ efflux in dark. $\mathrm{H}_{2} \mathrm{O}$ flux $\left(\mathrm{mmol} \mathrm{m} \mathrm{m}^{-2} \mathrm{~s}^{-1}\right)=\Delta \mathrm{H}_{2} \mathrm{O} \quad(\mathrm{V} \times 1000) /(\mathrm{A} \times 22.414 \times$ $1000 \times 60$ ), where $\Delta \mathrm{H}_{2} \mathrm{O}$ is the difference of water vapour pressure between the air supply and the chamber pressure in millibars (CPY-3, operators manual version 3.10; PP Systems).

\section{Climate and microclimate}

Continuous measurements of PAR, UV-B and air temperature were recorded at the meteorological station $1 \mathrm{~km}$ from the experimental site, extracted from the ZERO database (Climate Basic) at the Zackenberg webpage (www.zackenberg.dk) and daily means are presented in
Fig. 2. The ambient UV-B radiation was monitored with an erythema-weighted UV-Biometer (Model 501; Solar light, Philadelphia, PA), incoming PAR radiation (LI190SA; Li-Cor, Nebraska, NE) and air temperature in 2-m height (HMP 35D; Vaisala, Helsinki, Finland).

Microclimatic measurements were conducted in each plot. The leaf temperature was recorded at five different places in the canopy, representing both shaded and light exposed parts, with a non-contact IR thermometer (Raynger MX2; Raytek, Berlin, Germany) just before the canopy chamber was attached. Surface volumetric soil moisture content $\left(\mathrm{m}^{3} \mathrm{~m}^{-3}\right)$ in 0-6 cm depth (Theta-probe type ML2x; Delta-T Devices Ltd., Cambridge, UK) and soil temperature in 5 and $10 \mathrm{~cm}$ depth (multi-thermometer) were measured at two different places outside the chamber base just after the detachment of the canopy chamber. PAR was recorded during the measurements by a sensor in the canopy chamber.

\section{Leaves}

The detached fresh leaves were digitally photographed immediately after the field measurements, and their areas were determined against a reference of known area by a pixel counting programme (S. Danbæk, Institute of Biology, University of Copenhagen). Subsequently, the leaves were dried at $80^{\circ} \mathrm{C}$ for $48-62 \mathrm{~h}$, and their dry weights were determined. Total soluble flavonoids were
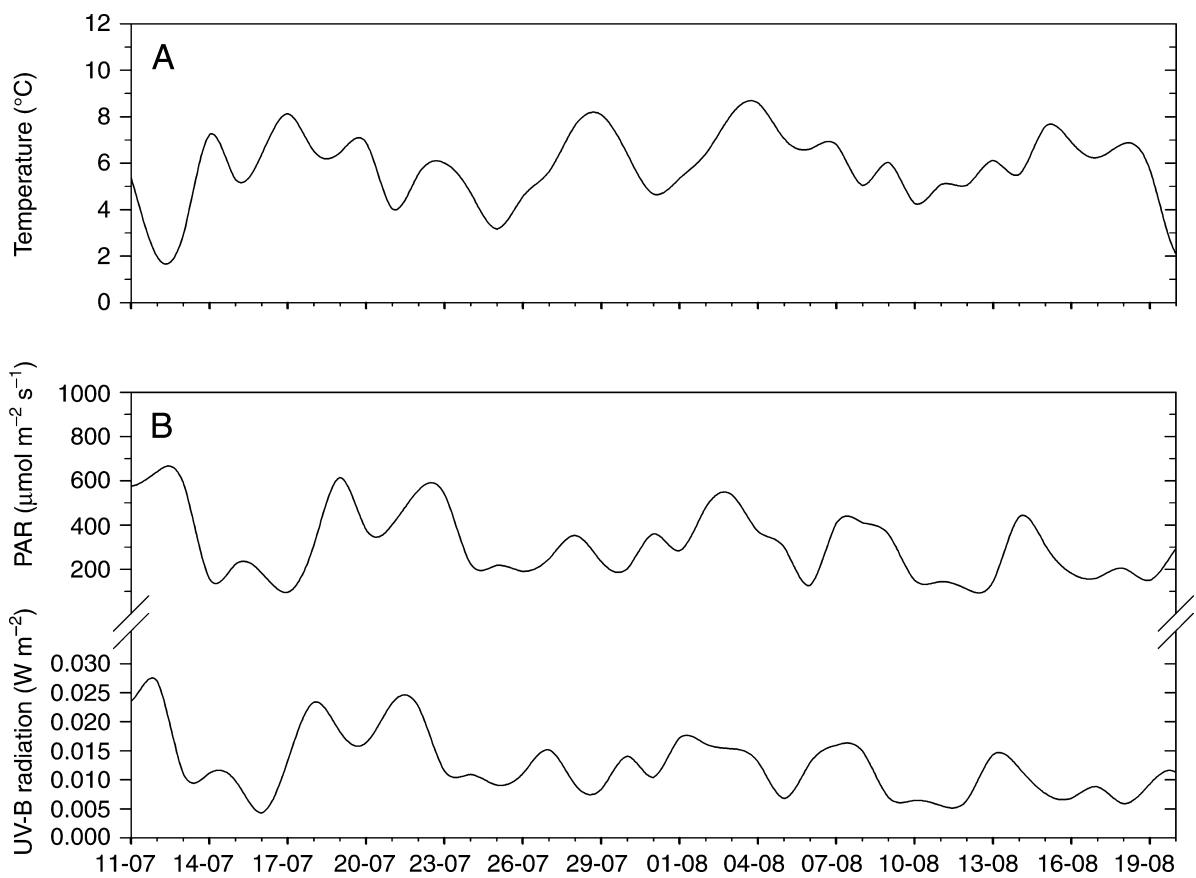

Fig. 2. (A) Air temperature in $2 \mathrm{~m}$ height. (B) PAR (upper) and daily erythema-weighted UV-B dose (lower). Twenty-four-hour means recorded at the meteorological station at Zackenberg from 11 July to 20 August 2002 are shown. 
extracted by a three-step procedure: (1) heating $\left(60^{\circ} \mathrm{C}\right)$ of pulverized leaves in $5 \mathrm{ml}$ methanol for $3 \mathrm{~min}$, (2) shaking 10 min after adding $5 \mathrm{ml} \mathrm{HCl}-\mathrm{H}_{2} \mathrm{O}$-methanol (1:20:79), (3) diluting the supernatant by 10 in $\mathrm{HCl}-\mathrm{H}_{2} \mathrm{O}-$ methanol (1:20:179) after centrifugation at $1200 \mathrm{~g}$ for $10 \mathrm{~min}$ (Caldwell 1968). After additional 10-min shaking, the UV absorption was measured with a spectrophotometer (U-2010; Hitachi, Tokyo, Japan) in the interval between 280 and $315 \mathrm{~nm}$ by $0.2 \mathrm{~nm}$ increments. The area below the absorption curve was calculated as the sum of all absorptions in the scanned range. Carbon and nitrogen concentrations were determined on a Leco Truspec CN elemental determinator (Leco Corporation, St Joseph, MI).

\section{Statistical analysis}

Statistical analyses were conducted using the general linear model (GLM) procedure (SAS Institute Inc. 1999, version 8.02). Levene's test was used to test for homogeneity of variance and appropriate transformations were applied in cases with heteroscedasticity. Treatment effects on fluorescence variables were tested across all measurements during the season by one-way ANOVA. Gas exchange and microclimatic data were tested with a repeated measurement ANOVA, with treatment as factor and day repeated within each plot. This was to take into account that the same experimental unit (the plot) was measured several times during the season. In cases of significant treatment effects, these analyses were followed by tests of treatment differences using Tukey's test. All values presented here are non-transformed. Differences are considered at the $P<0.05$ level. To exclude the possible interaction between treatment and microclimate on the gas exchange variables, Pearson's correlations between gas exchange variables and microclimatic parameters were calculated. If the correlations were significant $(P<0.05)$, then parameters were included in the ANOVA as covariates.

\section{Results}

\section{Chl a fluorescence}

The derived quantum efficiencies were slightly lower throughout the season for plants in ambient UV-B compared with plants in reduced UV-B. The TR $/ A B S=$ $F_{V} / F_{M}$ (efficiency by which an absorbed photon will be trapped by the PSII RC, with the resultant reduction of $\mathrm{Q}_{\mathrm{A}}$ ) was significantly decreased, where the $\mathrm{ET}_{\mathrm{O}} / \mathrm{TR}_{\mathrm{O}}$ (efficiency by which an electron residing on $\mathrm{Q}_{\mathrm{A}}{ }^{-}$will enter the intersystem electron transport chain) was only marginally decreased, but not significantly, in ambient UV-B. In combination, this led to a slight, but significant, decrease in $\mathrm{ET}_{\mathrm{o}} / \mathrm{ABS}$ (quantum yield for electron transport) (Fig. 3, Table 1).

The derived specific fluxes per active PSII RC were almost all affected by treatment. Both the ABS/RC (absorption flux of photons per active RC) and the $T R_{\mathrm{o}} /$ $\mathrm{RC}$ (maximum trapping rate by which an exciton is trapped per active PSII RC) were significantly higher in ambient UV-B. In spite of this, $\mathrm{ET}_{\mathrm{o}} / \mathrm{RC}$ (electron transport to intersystem chain per active PSII RC) did not differ because of the significantly higher $\mathrm{DI}_{\mathrm{o}} / \mathrm{RC}$ (effective dissipated flux of untrapped excitons per active PSII RC) in ambient UV-B (Fig. 3, Table 1). The estimated number of active PSII RC per leaf CS using $F_{M}, R C / C S_{M}$, was significantly decreased in ambient UV-B (Fig. 3, Table 1).

The derived phenomenological fluxes per excited leaf sample $C S$, estimated from $F_{M}$, were reduced or unaffected in ambient UV-B across all measurements (Fig. 3, Table 1) except for late August (data not shown). The ABS/ $\mathrm{CS}_{\mathrm{M}}$ (photons absorbed, at $\mathrm{F}_{\mathrm{M}}$, by antenna molecules associated with all PSII RCs per leaf CS) was decreased in ambient UV-B, although not significantly (Fig. 3, Table 1) because of the late August increase for plants in ambient UV-B only (data not shown). The combination of significantly decreased $\mathrm{TR}_{\alpha} / \mathrm{CS}_{M}$ (trapping rate of excitons that will lead to $\mathrm{Q}_{\mathrm{A}}$ reduction per leaf $\mathrm{CS}$ ) and increased $\mathrm{DI} / \mathrm{CS}_{\mathrm{M}}$ (effective dissipated rate of untrapped excitons per leaf $\mathrm{CS}$ ) led to a significantly reduction in $\mathrm{ET}_{\mathrm{O}} / \mathrm{CS}_{\mathrm{M}}$ (electron transport rate per leaf CS) in ambient UV-B. This pattern was seen throughout the season.

The overall performance of PSII was assessed by the performance indexes (both based on same quantum efficiencies) and both the $\mathrm{Pl}_{\mathrm{Abs}}$ (related to equal absorption) and $\mathrm{PI}_{\mathrm{CSm}}$ (related to the per CS level by the

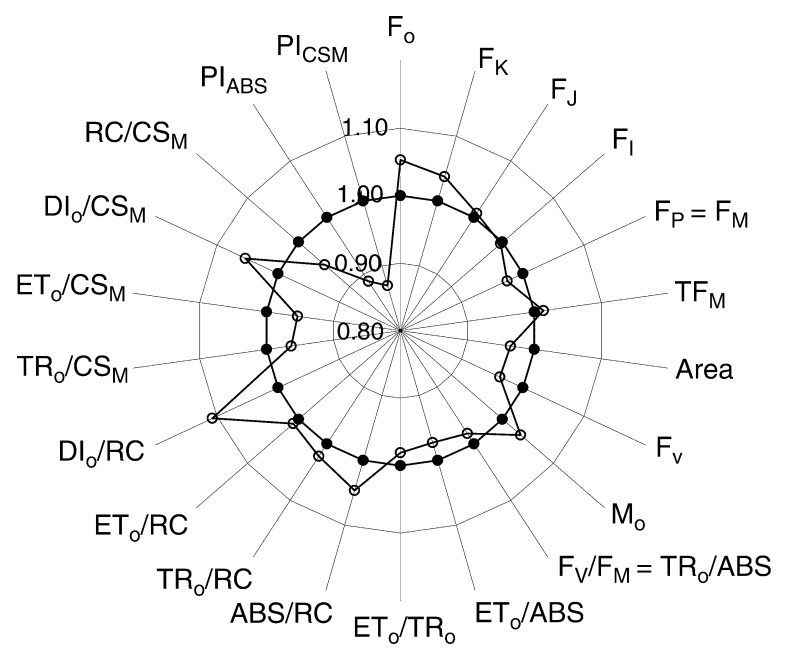

Fig. 3. Radar plot of fluorescence parameters. Mean values from Table 1 are indexed with reduced UV-B as reference level. Reduced UV-B is depicted with closed circles and ambient UV-B as open circles. 
Table 1. Fluorescence variables. The numbers are seasonal means \pm SE tested by ANOvA with a general linear model followed by Tukey's test. Significant effects of treatment are shown by different letters. The resulting values of individual $F$-test and probability of correct null hypothesis are given. All data are extracted from the fast fluorescence transient O-J-I-P, according to Strasser et al. (2004). ABS, absorption energy flux; CS, excited cross-section of leaf sample; DI, dissipation energy flux at the level of the antenna chlorophylls; $E T$, flux of electrons from $Q_{A}^{-}$into the intersystem electron transport chain; $\varphi_{P o}$ maximal quantum yield of primary photochemistry; $\psi_{0}$, efficiency by which a trapped exciton, having triggered the reduction of $Q_{A}$ to $Q_{A}^{-}$, can move an electron further than $\mathrm{Q}_{\mathrm{A}}^{-}$into the electron transport chain; $\mathrm{RC}, \mathrm{PSII}$ reaction centre; $\mathrm{RC} / \mathrm{CS}$, concentration of reaction centres per excited CS of leaf sample; $T R$, excitation energy flux trapped by an $R C$ and utilized for the reduction of $\mathrm{Q}_{\mathrm{A}}$ to $\mathrm{Q}_{\mathrm{A}}^{-} ; \mathrm{Pl}$, performance index. Note the distinction between measured and derived parameters. See Materials and Methods and Introduction sections for an introduction to JIP-test, Fig. 2 for the indexed values of fluorescence parameters depicted as radar plot and Fig. 1 for pipeline models outlining specific and phenomenological fluxes.

\begin{tabular}{|c|c|c|c|c|}
\hline Variable & Reduced UV-B & Ambient UV-B & $F$ value & Prob $F$ \\
\hline \multicolumn{5}{|l|}{ Measured parameters } \\
\hline $\mathrm{F}_{\mathrm{o}}=\mathrm{F}_{50 \mu \mathrm{s}}$ & $210.4^{B} \pm 2.2$ & $221.5^{\mathrm{A}} \pm 3.3$ & 9.62 & 0.0020 \\
\hline$F_{K}=F_{300 \mu s}$ & $292.3^{B} \pm 2.7$ & $303.3^{A} \pm 3.6$ & 6.96 & 0.0085 \\
\hline$F_{J}=F_{2 m s}$ & $493.2^{A} \pm 4.2$ & $496.8^{A} \pm 4.5$ & 0.034 & 0.5588 \\
\hline $\mathrm{F}_{1}=\mathrm{F}_{30 \mathrm{~ms}}$ & $642.4^{\mathrm{A}} \pm 5.7$ & $640.3^{A} \pm 5.8$ & 0.07 & 0.7868 \\
\hline $\mathrm{F}_{\mathrm{P}}=\mathrm{F}_{\mathrm{M}}$ & $823.2^{\mathrm{A}} \pm 7.9$ & $811.7^{A} \pm 7.7$ & 1.01 & 0.3161 \\
\hline $\mathrm{T}_{\mathrm{FM}}$ & $834.1^{\mathrm{A}} \pm 14.5$ & $845.6^{\mathrm{A}} \pm 14.7$ & 0.38 & 0.5376 \\
\hline Area & $28307^{A} \pm 502$ & $27302^{A} \pm 482$ & 2.17 & 0.141 \\
\hline \multicolumn{5}{|l|}{ Derived parameters } \\
\hline \multicolumn{5}{|c|}{ Selected J-I-P-parameters } \\
\hline$F_{V}$ & $612.9^{\mathrm{A}} \pm 7.3$ & $590.0^{B} \pm 6.8$ & 5.55 & 0.0187 \\
\hline $\mathrm{F}_{\mathrm{V}} / \mathrm{F}_{\mathrm{M}}$ & $0.7345^{A} \pm 0.0032$ & $0.7211^{B} \pm 0.0036$ & 8.85 & 0.030 \\
\hline$(\mathrm{dV} / \mathrm{dt})_{0}=\mathrm{M}_{\mathrm{o}}$ & $0.5533^{B} \pm 0.0068$ & $0.5731^{A} \pm 0.0082$ & 3.36 & 0.0671 \\
\hline \multicolumn{5}{|c|}{ Quantum efficiencies } \\
\hline$\varphi_{\text {Po }}=\mathrm{TR}_{\mathrm{O}} / \mathrm{ABS}$ & $0.7345^{A} \pm 0.0032$ & $0.7211^{B} \pm 0.0037$ & 8.84 & 0.0030 \\
\hline$\varphi_{\mathrm{Eo}}=\mathrm{ET}_{\mathrm{o}} / \mathrm{ABS}$ & $0.3915^{A} \pm 0.0032$ & $0.3808^{B} \pm 0.0033$ & 5.07 & 0.0246 \\
\hline$\psi_{\mathrm{o}}=\mathrm{ET}_{\mathrm{o}} / \mathrm{TR}_{\mathrm{o}}$ & $0.5303^{A} \pm 0.0031$ & $0.5201^{A} \pm 0.0034$ & 0.39 & 0.5340 \\
\hline \multicolumn{5}{|l|}{ Specific fluxes } \\
\hline $\mathrm{ABS} / \mathrm{RC}$ & $1.6230^{B} \pm 0.0195$ & $1.698^{A} \pm 0.0242$ & 6.79 & 0.0093 \\
\hline $\mathrm{TR}_{\mathrm{o}} / \mathrm{RC}$ & $1.1637^{B} \pm 0.0073$ & $1.1896^{\mathrm{A}} \pm 0.0093$ & 5.93 & 0.0150 \\
\hline $\mathrm{ET}_{\mathrm{O}} / \mathrm{RC}$ & $0.6104^{\mathrm{A}} \pm 0.0037$ & $0.6165^{A} \pm 0.0039$ & 2.02 & 0.1553 \\
\hline $\mathrm{DI}_{\mathrm{o}} / \mathrm{RC}$ & $0.4593^{B} \pm 0.0142$ & $0.5086^{A} \pm 0.0173$ & 5.65 & 0.0176 \\
\hline \multicolumn{5}{|c|}{ Phenomenological fluxes } \\
\hline$A B S / C S_{M}=F_{M}$ & $823.2^{A} \pm 7.9$ & $811.7^{\mathrm{A}} \pm 7.7$ & 1.01 & 0.3161 \\
\hline $\mathrm{TR}_{\mathrm{o}} / \mathrm{CS}_{\mathrm{M}}$ & $612.8^{A} \pm 7.2$ & $590.2^{B} \pm 6.8$ & 5.55 & 0.0187 \\
\hline $\mathrm{ET}_{\mathrm{O}} / \mathrm{CS}_{\mathrm{M}}$ & $330.0^{A} \pm 4.8$ & $314.8^{B} \pm 4.5$ & 4.94 & 0.0264 \\
\hline $\mathrm{DI}_{\mathrm{O}} / \mathrm{CS}_{\mathrm{M}}$ & $210.3^{B} \pm 2.2$ & $221.5^{\mathrm{A}} \pm 3.4$ & 9.62 & 0.0020 \\
\hline \multicolumn{5}{|c|}{ Density of PSII reaction centres } \\
\hline $\mathrm{RC} / \mathrm{CS}_{\mathrm{M}}$ & $542.9^{\mathrm{A}} \pm 7.6$ & $514.9^{B} \pm 7.4$ & 7.45 & 0.0065 \\
\hline \multicolumn{5}{|c|}{ Performance indexes } \\
\hline $\mathrm{Pl}_{\mathrm{ABS}}$ & $2.48^{A} \pm 0.06$ & $2.20^{B} \pm 0.05$ & 9.51 & 0.0021 \\
\hline $\mathrm{Pl}_{\text {CSM }}$ & $2171^{A} \pm 61$ & $1888^{B} \pm 54$ & 12.03 & 0.0005 \\
\hline
\end{tabular}

approximated absorption) showed same significantly decreased pattern during season in ambient UV-B (Fig. 3, Table 1).

The seasonal fluctuations of almost all above parameters showed a steep increase until late July and then parameters were stabilized at a plateau until mid-August and hereafter decreased throughout the season (data not shown).

\section{Gas exchange}

The canopy net photosynthesis showed an almost constant significant difference between reduced UV-B and ambient UV-B plots from the beginning of the season until mid-August (Fig. 4A). The mean seasonal net photosynthesis was significantly decreased in ambient UV-B, also with PAR or leaf temperature as covariates, being $77 \%$ of $P_{n}$ at reduced UV-B (Table 2). The seasonal fluctuations of net photosynthesis for both treatments follow, to some extent, the variation in PAR. Net photosynthesis was at its maximum in late July, where after a plateau was maintained until the late August autumn decrease. No difference between treatments was observed in late August.

Respiration showed a declining trend through season for both treatments (Fig. 4B). The mean seasonal 

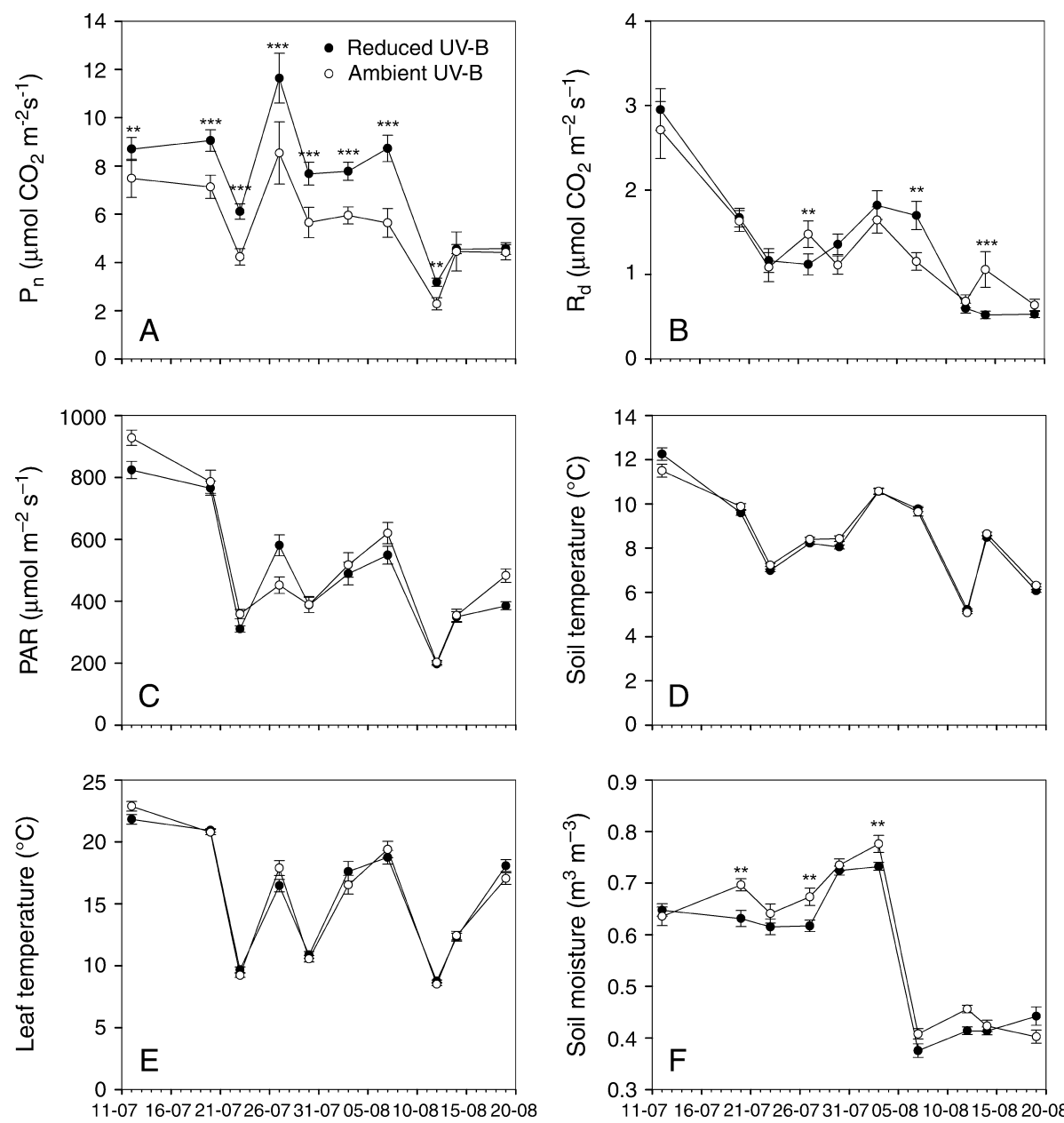

Fig. 4. (A) Net photosynthesis and (B) dark respiration on canopies of Vaccinium uliginosum. The daily means \pm sE during season are shown. Net photosynthesis is depicted as circles and respiration as squares. (C) PAR inside chamber during measurement, (D) soil temperature, (E) leaf temperature and (F) soil moisture in the Vaccinium canopies during season. Closed symbols represent reduced UV-B and open symbols represent ambient UV-B. $* * * P<0.0010, * * P<0.0100$ and ${ }^{*} P<0.1000$ tested by ANOvA with a general linear model followed specifying the repeated measurements (see Statistical analysis).

respiration in ambient UV-B plots was marginally lower than in reduced UV-B (except 27 July and 14 August) but only as a weak statistical tendency. Across all measurements through the season, there was a significant effect on respiration with soil temperature as covariate.

\section{Microclimate}

Leaf and soil temperatures were almost identical throughout the season, but soil water content differed significantly between treatments $(P<0.0001)$, being higher in ambient UV-B plot than in UV-B reduced plots (Fig. 4F).

Table 2. Gas exchange variables measured. The numbers are seasonal means \pm SE tested by ANOva with a general linear model specifying the repeated measurements. PAR inside the chamber, leaf temperature or soil temperature were included as covariates (see Statistical analysis). The resulting value and probability of $F$-statistics is given.

\begin{tabular}{llll}
\hline Variable & Reduced UV-B & Ambient UV-B & Prob $F$ \\
\hline Net photosynthesis $\left(P_{\mathrm{n}}, \mu \mathrm{mol} \mathrm{CO} \mathrm{C}^{-2} \mathrm{~s}^{-1}\right)$ & $7.20 \pm 0.19$ & $5.55 \pm 0.22$ & 0.0001 \\
Dark respiration $\left(\mathrm{R}_{\mathrm{d}} \mu \mathrm{mol} \mathrm{CO} \mathrm{m}^{-2} \mathrm{~s}^{-1}\right)$ & $1.34 \pm 0.05$ & $1.32 \pm 0.06$ & 0.0999 \\
Gross photosynthesis $\left(\mathrm{Pg}, \mu \mathrm{mol} \mathrm{CO}_{2} \mathrm{~m}^{-2} \mathrm{~s}^{-1}\right)$ & $8.54 \pm 0.22$ & $6.88 \pm 0.27$ & 0.0407 \\
Transpiration $\left(\mathrm{Tr}, \mathrm{mmol} \mathrm{H} \mathrm{m} \mathrm{m}^{-2} \mathrm{~s}^{-1}\right)$ & $1.94 \pm 0.05$ & $1.94 \pm 0.06$ & 0.9262 \\
\hline
\end{tabular}


In general, the fluctuations in temperatures followed the fluctuations in the PAR level (Fig. 4C-E), with soil temperature response being relatively dampened (Fig. $4 f$ ).

\section{Growth and leaf chemistry}

Growth parameters probably depends strongly on the initial values; hence, no difference in the measured mean leaf biomass, stem biomass and total aboveground biomass per plot as well as the estimated leaf area, specific leaf area (SLA) and leaf area index (LAI) was found between treatments (data not shown). No differences in leaf concentrations of carbon, nitrogen and $\mathrm{C} / \mathrm{N}$ ratio were observed between the treatments. The leaf content of total soluble UV-B-absorbing compounds was significantly higher in ambient UV-B plots (80 area units) compared with the UV-B reduced plots (64 area units) $(P<0.045)$.

\section{Discussion}

\section{PSII performance}

The JIP-test reveals information on different scales of the performance of the PSII photosynthetic machinery and has proven sensitive to detect stress (Clark et al. 2000, Krüger et al. 1997). It has been pointed out that the PI indexes, similar to $\mathrm{CO}_{2}$ assimilation, are regulated by accumulation of effects on both the biophysical and the biochemical performance of the photosynthetic apparatus (van Heerden et al. 2003). However, only one such investigation has been carried out in UV-B-exclusion experiments (Albert et al. 2005), but it was not coupled to photosynthetic rates, despite the potential new insight. For $V$. uliginosum, the relations between quantum efficiencies, specific fluxes per active PSII RC and phenomenological fluxes per leaf CS closely followed the pattern reported for $S$. arctica from the nearby experimental site (Albert et al. 2005) and was clearly negatively affected by ambient UV-B at all levels. This is elaborated in detail below.

Vaccinium quantum efficiencies were reduced in ambient UV-B, clearly indicating a slightly lower potential to process light energy through PSII. Moving onto the specific fluxes per active PSII RCs, the absorption flux of photons per active $R C, A B S / R C$, was higher in ambient UV-B. Probably this reflects a larger average antenna size per PSII RC. As the antennae size is calculated average values as total absorbing $\mathrm{Chl}$ per total fully active $\left(\mathrm{Q}_{\mathrm{A}}\right.$ reducing) PSII $\mathrm{RCs}$, and it can be suggested that the antennae size would be increased if RCs were converted into heat sinks or other regrouping of antennas from active RCs to inactive RCs occurred (Strasser et al. 1995, van Heerden et al. 2003). This lead to a larger maximum trapping rate of excitons per active PSII RC, $T R_{o} / R C$, but because of the higher effective dissipation of untrapped excitons per active PSII RC, $\mathrm{DI}_{\mathrm{O}} /$ $\mathrm{RC}$, this summed up to the same level of electron transport per PSII RC, $\mathrm{ET}_{\mathrm{o}} / \mathrm{RC}$, in both treatments. Therefore, it is reasonable that the integrated response of individual fluxes per active PSII RCs into the performance index, $\mathrm{Pl}_{\mathrm{Abs}}$, confirms the lower performance at this level. The combination of equal electron transport per active PSII RC $\left(\mathrm{ET}_{\mathrm{o}} / \mathrm{RC}\right)$ in both treatments and the decreased number of active PSII RCs per leaf CS, $\mathrm{RC} / \mathrm{CS}_{\mathrm{M}}$, clearly indicate a reduced potential of electron transport capacity per leaf CS in ambient UV-B. This is in accordance with the interpretation by Albert et al. (2005), linking this particular behaviour of parameters between levels in response to UV-B. Indeed, a reduction in phenomenological fluxes per leaf CS in ambient UV-B was found and resulted in a $5 \%$ decreased electron transport per leaf $\mathrm{CS}, \mathrm{ET}_{\mathrm{O}} / \mathrm{CS}_{\mathrm{M}}$. On the other hand, if phenomenological fluxes were estimated using $\mathrm{F}_{\mathrm{o}}$, an unchanged $\mathrm{ET}_{\mathrm{o}} / \mathrm{CS}_{\mathrm{o}}$ were observed (data not shown). This point to care when estimating phenomenological fluxes because they are directly affected by the magnitude of the here chosen estimators, $F_{o}$ or $F_{M}$, and also the quantum efficiencies. This may be seen as a weakness of the JIP-test but also stresses the assumption that estimators theoretically shall reflect the absorption energy flux per excited CS of leaf sample (ABS/ CS) in arbitrary units in the dark-adapted state (Strasser et al. 2004), may not always be easy to apply. However, independent of chosen estimators, the dissipation of untrapped photons per leaf CS was consistently highest in ambient UV-B. These points to the particular importance of ambient UV-B impact on energy dissipation processes. Differences in response pattern in quantum efficiencies and phenomenological fluxes are integrated in the performance indexes $\left[\mathrm{PI}_{\mathrm{CSm}}\right.$ (Table 1) and also $\mathrm{Pl}_{\mathrm{CSo}}$ (not shown)]. Their reduction clearly indicates a reduced overall processing of light energy per leaf sample CS in ambient UV-B. Hence, these response patterns do support the consideration that $\mathrm{PI}$ indexes are sensitive and overall integrating parameters for PSII performance (Clark et al. 2000, Strasser et al. 2000).

High irradiance levels above photosynthetic capacity decrease PSII activity (Krause and Weiss 1991), whereas medium-to-low irradiance levels do not. Therefore, the differences of PAR levels between filtered treatments are considered. Because the ambient UV-B treatment exposed the plants to a higher proportion of PAR compared with UV-B reduced treatment, the plants in ambient UV-B treatment could be argued to be more susceptible to a decrease in PSII activity. Therefore, we cannot rule out a possible small negative effect of PAR on the decrease in PSII activity. However, the much higher proportional 
change in UV-B level do strengthen that the impact on PSII activity is because of ambient UV-B.

Altogether, these findings clearly indicate a negatively affected PSII performance and lower potential of electron transport capability in the chloroplasts of the plants exposed to ambient UV-B.

\section{Photosynthetic performance}

The gas exchange measured in the canopy plots is supposed, predominately, to be affected by the aboveground plant parts only because of the elevated pressure in the chamber. The sparse graminoids and the bottom layer of moss are thought to have a minor effect on gas exchange, and therefore, the main part of the gas exchange is ascribed to the canopy of Vaccinium alone.

In addition to the difference in UV-B levels, the plants in the filtered controls received approximately $11 \%$ more PAR compared with plants in reduced UV-B. As argued below, PAR is not a confounding factor here. The UV-B effects were very significant also when taking PAR levels into consideration. The PAR and UV-B effects were separated, and the PAR effect excluded by including PAR, measured simultaneously with each single gas exchange recording, in the statistical analysis as covariate (see Statistical analysis section). Moreover, it could be argued that light unsaturated plants exposed to different PAR levels could translate into different photosynthetic rates, why PAR levels at the time of measurement could be of special importance. This was not the case as the variation in the PAR levels, which alternated random between treatments, did not translate into higher photosynthesis in controls even when PAR levels were highest here. Additionally, if plants are argued to be measured under light-saturated conditions, the effects PAR should be equivalent and as such ruled out adding further to the UV-B effect. Finally, we argue that even if the approximately $11 \%$ less PAR level in UV-B reduced plots compared with filtered controls potentially could result in adjustments of photosynthetic capacity, then no such responses were seen as the photosynthesis rates were significantly highest in reduced UV-B.

No other reports on photosynthesis rates in relation to UV-B in the high Arctic are available, but decreased rates have been reported from other ecosystems. Decreased net photosynthesis for plants exposed to the realistic supplemental UV-B irradiance is in agreement with several previous reports (Baker et al. 1997, Keiller and Holmes 2001, Keiller et al. 2003), showing inhibition of photosynthesis in the field. Effects on growth have also been reported from exclusion experiments (Gonzalez et al. 1998, Krizek et al. 1997). Other studies performed with supplemental UV-B (Allen et al. 1999) did not find such effects. During the senescence period, the treatment differences disappeared. This is different from earlier findings of UV-B promoted senescence in beech (Zeuthen et al. 1997). Although difficulties in results comparisons because of different methodologies, supplemental UV-B vs UV-B exclusion, have been pointed to (Flint et al. 2003, Rousseaux et al. 2004), several mechanisms have been suggested to be responsible for UV-B-induced stress on photosynthesis. Effects on gene expression in field conditions have been shown (Keiller et al. 2003), while indoor supplementation studies have identified changes in stomatal conductance (Negash and Björn 1986, Teramura et al. 1983), Rubisco content, reductions in capacity for photosynthetic electron transport $\left(J_{\max }\right)$ and maximum carboxylase activity of ribulose 1,5-bisphosphate carboxylase/oxygenase $\left(V_{c, \max }\right)$ (Allen et al. 1997, Baker et al. 1997, He et al. 1993, Jordan et al. 1992) as possible limitations on photosynthesis. These reductions have been argued to be caused by unrealistic high UV-B irradiances (Allen et al. 1998). Some studies suggested that PSII is the primary target of UV-B damage, reducing PSII activity (Melis et al. 1992, Strid et al. 1990) and abundance of D1 (Jansen et al. 1996, Nogués and Baker 1995), while other studies have shown that photosynthetic inhibition can occur without any measurable effect on PSII (Allen et al. 1999, Middleton and Teramura 1993). Indeed, it may not always be realistic to expect a close correlation between net photosynthesis and loss of functional PSII complexes, especially if PSII complexes are in excess. Hence, Lee et al. (1999) demonstrated, in vivo on Capsicum annuum, a limitation of photosynthetic capacity to be present only after a $40 \%$ loss of functional PSII complexes.

In this study, the lower quantum efficiencies, phenomenological fluxes, performance indexes and number of active RCs in ambient UV-B clearly indicated that ambient $U V$-B reduces the potential of primary photochemistry. The parameters may be criticized for being potentials and not actual fluxes because they are investigated on predarkened leaves. Ideally, the analysis of fluorescence parameters has to be evaluated in relation to incoming PAR, leaf absorbance, etc., while further studies should include simultaneous measurements of gas exchange and fluorescence parameters during light exposure. With these precautions, the observed reduction in net photosynthesis is at least partly explained by decreased PSII performance, although effects on other parts of the photosynthetic machinery, e.g. direct effects on the Calvin cycle function, are indeed very possible, especially when comparing the relative differences in treatment effects between PSII function and photosynthesis. The parallel seasonal variation in PSII performance and net photosynthesis strengthen linking of the impact of increased PSII performance to increased net photosynthesis. 


\section{UV-B-absorbing compounds}

Enhanced synthesis of flavonoids (Caldwell et al. 1998, Searles et al. 2001) and hydroxycinnamates (Burchard et al. 2000, Ruhland et al. 2005) is a well-known response to increased UV-B radiation, why UV-B-absorbing compounds were expected to be more abundant in ambient UV-B compared with UV-B-excluded plots. This was confirmed in this study. In addition, parallel results were found in a 6-year UV-B-exclusion study on the same species on a nearby site (Albert et al., unpublished data). In comparison, studies carried out with supplemental $U V-B$ in the sub-Arctic on V. uliginosum found a tendency to an increase in UV-B-absorbing compounds in response to supplemental UV-B (Phoenix et al. 2000, Semerdjieva et al. 2003a), but at the same time, a significant depletion in wall-bound pigments was found (Semerdjieva et al. 2003a). In contrast, no significant change in whole leaf extracts of UV-B-absorbing compounds (including cellular and epicuticular extracts) in sub-Arctic V. uliginosum was found in a 3-year UV-Bexclusion study (Phoenix et al. 2002). Together these findings clearly indicate differences in the performance of this species in response to UV-B. It has been suggested that the vulnerability to UV-B irradiance may be exacerbated in simple canopy systems in arctic vegetation (Phoenix et al. 2000). Moreover, sub-Arctic V. uliginosum may receive more $U V$-B irradiance than other dwarf shrubs as it is a strong competitor for light as it orients most leaves horizontally and has a very thin cuticle with no wax sculpturing and a low number of trichomes (Semerdjieva et al. 2003b). In comparison, high arctic $V$. uliginosum are even more exposed, and therefore, the differences could tentatively be interpreted as related to the UV-B doses in general or to differences between Arctic regions.

\section{Conclusions}

This study clearly demonstrated an almost immediate decrease in net photosynthesis in ambient UV-B compared with reduced UV-B. In addition, recordings of fluorescence induction curves and calculations of JIP-test parameters clearly demonstrated negative impact on PSII performance, i.e. $\mathrm{F}_{\mathrm{V}} / \mathrm{F}_{\mathrm{M}}$ and performance indexes in ambient UV-B. In combination with the finding of a high amount of UV-B-absorbing compounds, this could be interpreted that the plants to some degree are protected against UV-B and that underlying tissues are only slightly affected by ambient UV-B. However, the lower photosynthesis clearly demonstrated that this was not the case in the present study. It must therefore be stressed that synthesis of parameters on different scales is needed when evalu- ating the effects of UV-B. It should be noted that the $60 \%$ reduction of the UV-B irradiance used in this study implies a higher relative change in the UV-B load than many of the supplemental experiments do. Finally, the synthesis across scales within this study and the finding of the $24 \%$ increase in net photosynthesis when reducing the UV-B irradiance in particular clearly indicate that despite a clear UV-B avoidance response in canopies of $V$. uliginosum, this species is affected negatively by ambient UV-B levels.

Acknowledgements - The work was financially supported by the Danish Environmental Protection Agency, DANCEA (Danish Co-operation for Environment in the Arctic) grant 123/000-0212, the Danish Environmental Protection Board, Climate and Environment Support MST grant 127/01-0205 and the Danish natural Sciences Council grant 272-06-0230. Thanks to the logistic staff from the Danish Polar Center for making the experiments in Zackenberg possible. Skilful assistance from the staff in the Ecological-Chemical Laboratory, Department of Terrestrial Ecology, University of Copenhagen, is greatly appreciated.

\section{References}

Albert KR, Mikkelsen TN, Ro-Poulsen H (2005) Effects of ambient versus reduced UV-B radiation on high arctic Salix arctica assessed by measurements and calculations of chlorophyll-a fluorescence parameters from fluorescence transients. Physiol Plant 124: 208-226

Alenius CM, Vogelmann TC, Bornman J (1995) A three dimensional representation of the relationship between penetration of UV-screening pigments in leaves of Brassica napus. New Phytol 131: 297-302

Allen DJ, McKee IF, Farage PK, Baker NR (1997) Analysis of the limitation to $\mathrm{CO}_{2}$ assimilation on the exposure of leaves of two Brassica napus cultivars to UV-B. Plant Cell Environ 20: 633-640

Allen DJ, Nougúes S, Baker NR (1998) Ozone depletion and increased UV-B radiation: is there a real threat to photosynthesis? J Exp Bot 49: 1775-1788

Allen DJ, Nouges S, Morison JIL, Greenslade PD, Mcleod AR, Baker NR (1999) A thirty percent increase in UV-B has no impact on photosynthesis in well-watered and droughted pea plants in the field. Global Chang Biol 5: 235-244

Baker NR, Nougés S, Allen DJ (1997) Photosynthesis and photoinhibition. In: Lumsden PJ (ed) Plants and UV-B Responses to Environmental Change, Society for experimental biology, Seminar Series 64. Cambridge University Press, Cambridge, UK, pp 95-112

Björn LO, Callaghan TV, Gehrke C, Gwynn-Jones D, Lee JA, Johanson U, Sonesson M, Buck ND (1999) Effects of ozone 
depletion and increased ultraviolet- $B$ radiation on northern vegetation. Polar Res 18: 331-337

Bredahl L, Ro-Poulsen H, Mikkelsen TN (2004) Reduction of the ambient $U V$-B radiation in the high Arctic increases $\mathrm{F}_{\mathrm{v}} / \mathrm{F}_{\mathrm{m}}$ in Salix arctica and Vaccinium uliginosum and reduces stomatal conductance and internal $\mathrm{CO}_{2}$ concentration in S. arctica. Arct Antarct Alp Res 36: 364-369

Burchard P, Bilger W, Weissenböck G (2000) Contribution of hydroxycinnamates and flavonoids to epidermal shielding of UV-A and UV-B radiation in developing rye primary leaves as assessed by ultraviolet-induced chlorophyll fluorescence measurements. Plant Cell Environ 23: 1373-1380

Caldwell MM (1968) Solar ultraviolet radiation as an ecological factor for alpine plants. Ecol Monogr 39: 243-268

Caldwell MM, Flint SD (1994) Stratospheric ozone reduction, solar UV-B radiation and terrestrial ecosystems. Clim Change 28: 375-394

Caldwell MM, Björn LO, Bornman JF, Flint SD, Kulandaivelu G, Teramura AH, Tevini M (1998) Effects of increased solar ultraviolet radiation on terrestrial ecosystems. J Photochem Photobiol B Biol 46, 40-52

Callaghan TV, Jonasson S (1995) Arctic terrestrial ecosystems and environmental change. Philos Trans R Soc Lond A 352: 259-276

Clark AJ, Landolt W, Bucher JB, Strasser RJ (2000) How wind affects the photosynthetic performance of trees: quantified with chlorophyll-a fluorescence and open-top chambers. Photosynthetica 38: 349-360

Cybulski WJ, Peterjohn WT (1999) Effects of ambient UV-B radiation on the aboveground biomass of seven temperate-zone plant species. Plant Eco 145: 175-181

Day TA, Ruhland CT, Xiong FS (2001) Influence of solar ultraviolet-B radiation on Antarctic terrestrial plants: results from a 4-year field study. J Photochem Photobiol B Biol 62: 78-87

Flint SD, Ryel RJ, Caldwell MM (2003) Ecosystem UV-B experiments in terrestrial communities: a review of recent findings and methodologies. Agri For Meteor 120: 177-189

Gehrke C, Johanson U, Björn LO, Callaghan TV, Lee JA (1996) Effects of enhanced ultraviolet-B radiation on terrestrial sub-arctic ecosystems and implications for interactions with increased atmospheric $\mathrm{CO}_{2}$. Ecol Bull 45: 192-203

Gonzalez R, Mepsted E, Wellburn AR, Paul ND (1998) Non-photosynthetic mechanisms of growth reduction in pea (Pisum sativum L.) exposed to UV-B radiation. Plant Cell Environ 21: 23-32

He J, Huang L-K, Chow WS, Whitecross MI, Anderson JM (1993) Effects of supplementary ultraviolet-B radiation on rice and pea plants. Aust J Plant Physiol 20: 129-142

Jansen MAK, Gaba V, Greenberg BM, Mattoo AK, Edelman M (1996) Low threshold levels of ultraviolet-B in a background of photosynthetically active radiation trigger rapid degradation of the D2 protein of photosystem II.

Plant J 9: 693-696

Johanson U, Gehrke C, Björn LO, Callaghan TV (1995)

The effects of enhanced UV-B radiation on the growth of dwarf scrubs in a subarctic heathland. Func Ecol 9: 713-719

Jordan BR, He J, Chow WS, Anderson JM (1992) Changes in mRNA levels and polypeptide subunits of ribulose 1,5-biphospahte carboxylase in response to supplemental UV-B radiation. Plant Cell Environ 15: 91-98

Keiller DR, Holmes MG (2001) Effects of long term exposure to elevated UV-B radiation on the photosynthetic performance of five broad leaved tree species. Photosynth Res 67: 229-240

Keiller DR, Mackerness SA-H, Holmes MG (2003) The action of a range of supplementary ultraviolet (UV) wavelengths on photosynthesis in Brassica napus L. in the natural environment: effects on PSII, $\mathrm{CO}_{2}$ assimilation and level of chloroplast proteins. Photosynth Res 75: 139-150

Krause GH, Weiss E (1991) Chlorophyll fluorescence and photosynthesis: the basis. Annu Rev Plant Physiol Plant Mol Biol 42: 313-349

Krizek DT, Mirecki RM, Britz SJ (1997) Inhibitory effects of ambient levels of solar UV-A and UV-B radiation on growth of cucumber. Physiol Plant 100: 886-893

Krüger GHT, Tsmilli-Michael M, Strasser RJ (1997) Light stress provokes plastic and elastic modifications in structure and function of photosystem II in camelia leaves. Physiol Plant 101: 265-277

Lazár D (2006) The polyphasic chlorophyll a fluorescence rise measured under high intensity of exciting light. Func Plant Biol 33: 9-30

Lee H-Y, Chow WS, Hong Y-N (1999) Photoinactivation of photosystem II in leaves of Capsicum annuum. Physiol Plant 105: 377-384

Madronich S, McKencie RL, Björn LO, Caldwell MM (1998) Changes in biologically ultraviolet radiation reaching the Earth's surface. J Photochem Photobiol B Biol 46: 5-19

Melis A, Nemson JA, Harrison MA (1992) Damage to functional components and partial degradation of photosystem II reaction centre proteins upon chloroplast exposure to ultraviolet-B radiation. Biochim Biophys Acta 1109: 312-320

Middleton EM, Teramura AH (1993) The protective role of flavonol glycosides and carotenoids in protecting soybean form UV-B damage. Plant Physiol 103: 741-752

Negash L, Björn LO (1986) Stomatal closure by ultraviolet radiation. Physiol Plant 66: 360-364

Nogués S, Baker NR (1995) Evaluation of the role of damage to photosystem II in the inhibition of $\mathrm{CO}_{2}$ assimilation in pea plants on exposure to UV-B radiation. Plant Cell Environ 18: 781-787

Paul N (2001) Plant responses to UV-B: time to look beyond stratospheric ozone depletion? New Phytol 150: 1-8 
Phoenix GK, Gwynn-Jones D, Lee JA, Callaghan TV (2000) The impacts of UV-B radiation on the regeneration of a sub-arctic heath community. Plant Ecol 146: 67-75

Phoenix GK, Gwynn-Jones D, Lee JA, Callaghan TV (2002) Ecological importance of ambient solar ultraviolet radiation to a sub-arctic heath community. Plant Ecol 165: 263-273

Rasch M, Canning K (2003) Zackenberg Ecological Research Operations, 8th Annual Report. Danish Polar Center, Ministry of Science, Technology and Innovation, Copenhagen, Denmark, 80 pp

Rinnan R, Keinänen MM, Kasurinen A, Asikainen J, Kekki TK, Holopainen T, Ro-Poulsen H, Mikkelsen TN, Michelsen A (2005) Ambient UV radiation in the Arctic reduces root biomass and alters microbial community composition but has no effects on microbial biomass. Global Chang Biol 11: 564-574

Robson TM, Pancotto VA, Flint SD, Balleré CL, Sala OL, Scopel AL, Caldwell MM (2003) Six years of solar UV-B manipulations affect growth of Sphagnum and vascular plants in a Tierra del Fuego peatland. New Phytol 160: 379-389

Rousseaux MC, Balleré $\mathrm{CL}$, Giordano CV, Scopel AL, Zima AP, Szwarcberg-Bracchitta M, Searles PS, Caldwell MM, Diaz SB (1999) Ozone depletion and UV-B radiation: impact on plant DNA damage in southern America. Proc Nat Acad Sci U S A 96: 15310-15315

Rousseaux MC, Flint SD, Searles PS, Caldwell MM (2004) Plant responses to current solar UV-B radiation and to supplemented solar ultraviolet-B radiation simulating ozone depletion: an experimental comparison. J Photochem Photobiol B Biol 80: 224-230

Rozema J, Van de Staaij J, Björn LO, Caldwell MM (1997) UV-B as an environmental factor in plant life: stress and regulation. Trends Ecol Evol 12: 22-28

Ruhland CT, Xiong FS, Dennis Clark W, Day TA (2005) The influence of ultraviolet radiation on growth, hydroxycinnamc acids and flavonoids of Deschampsia antarctica during springtime ozone depletion in Antarctica. J Photochem Photobiol B Biol 81: 1086-1093

SAS Institute Inc. (1999) SAS/STAT Users guide, Version 8. Cary, NC

Searles PS, Flint SD, Caldwell MM (2001) A meta-analysis of plant studies simulating stratospheric ozone depletion. Oecologia 127: 1-10

Semerdjieva SI, Sheffield E, Phoenix GK, Gwynn-Jones D, Callaghan TV, Johnson GN (2003a) Contrasting strategies for UV-B screening in sub-Arctic dwarf shrubs. Plant Cell Environ 26: 957-964

Semerdjieva SI, Phoenix GH, Hares D, Gwynn-Jones D, Callaghan TV, Sheffield E (2003b) Surface morphology, leaf and cuticle thickness of four dwarf shrubs from a sub-Arctic heath following long-term exposure to enhanced levels of UV-B. Physiol Plant 117: 289-294

Strasser RJ, Srivastava A, Govindjee (1995) Polyphasic chlorophyll-a fluorescence transients in plants and cyanobacteria. J Photochem Photobiol B Biol 61: $32-42$

Strasser RJ, Tsimilli-Micheal M, Srivastava A (2000) The fluorescence transient as a tool to characterise and screen photosynthetic samples. In: Yunus M, Pathre U, Mohanty P (eds) Probing Photosynthesis: Mechanisms, Regulation and Adaptation. Taylor \& Francis, London, pp 445-483

Strasser RJ, Tsimilli-Micheal M, Srivastava A (2004) Analysis of the chlorophyll-a fluorescence transient. In: Papageogiou GC, Govindjee (eds) Advances in Photosynthesis and Respiration. Springer, Berlin, Germany, pp 321-362

Strid $\AA$, Chow WS, Anderson JM (1990) Effects of supplementary ultraviolet-B radiation on photosynthesis of in Pisum sativum. Biochim Biophys Acta 1020: 260-268

Teramura AH, Tevini M, Iwanzik W (1983) Effects of ultraviolet-B irradiance on plants during a mild winter stress. I. Effects of diurnal stomatal resistance. Physiol Plant 57: 175-180

Tsimilli-Michael M, Strasser RJ (2001) Fingerprints of climate changes on the photosynthetic apparatus' behaviour, monitored by the JIP-test. In: Walther G-R, Burga CA, Edwards PJ (eds) "Fingerprints" of Climate Changes Adapted Behaviour and Shifting Species Ranges. Kluwer Academic/Plenum Publishers, New York, pp 229-247 van de Staaij JWM, Ernst WHO, Hakvort HWJ, Rozema J (1995) Ultraviolet-B (280-320nm) absorbing pigments in the leaves of Silene vulgaris: their role in UV-B tolerance. J Plant Physiol 147: 75-80

van Heerden PDR, Merope TM, Krüger GHJ, Strasser RJ (2003) Dark chilling effects on soybean genotypes during vegetative development: parallel studies of $\mathrm{CO}_{2}$ assimilation, chlorophyll-a fluorescence kinetics O-J-I-P and nitrogen fixation. Physiol Plant 17: 476-491

WMO (2003) Scientific Assessment of Ozone Depletion: 2002. Global Ozone Research and Monitoring Project. Report no. 47. World Meteorological Organization, Geneva, $498 \mathrm{pp}$

Xiong FS, Day TH (2001) Effect of solar ultraviolet-B radiation during springtime ozone depletion on photosynthesis and biomass production of Antarctic vascular plants. J Plant Physiol 125: 738-751

Zeuthen J, Mikkelsen TN, Paludan-Møller G, Ro-Poulsen H (1997) Effects of increased UV-B radiation and elevated levels of tropospheric ozone on physiological processes in European beech (Fagus sylvatica). Physiol Plant 100: 281-290 